\title{
Key Aspects of Explication of Thinking in the Sergii Krymskyi's Legacy of the Soviet Period
}

\author{
Vitali Turenko \\ Ph.D., Junior Research Fellow, Taras Shevchenko National University of Kyiv \\ (Kyiv, Ukraine) \\ E-mail: vitali_turenko@ukr.net \\ https://orcid.org/0000-0003-0572-9119
}

\author{
Nataliia Yarmolitska \\ Ph.D., Researcher, Taras Shevchenko National University of Kyiv \\ (Kyiv, Ukraine) \\ E-mail: natasha63@ukr.net \\ https://orcid.org/0000-0002-1922-3496
}

\begin{abstract}
The article is devoted to the problem of thinking, which is one of the key issues of Sergii Krymskyi s legacy. The paper observes the analysis of the Soviet scientific legacy of the thinker conducted in the field of history of philosophy. The paper focuses is on the scholar's philosophical writings, which had been published between the 60 's-70 of the $20^{\text {th }}$ century. Authors observe the period of formation of "Kiev school of the logic of scientific cognition" in the "60s. Sergii Krymskyi was one of the leaders of the mentioned school and, along with his associates, proved that scientific thought cannot be subordinated to any ideological dictate. It is claimed that despite the pressure of the Marxist-Leninist ideology in his early years the scholar did not leave his intention to explore the nature of logical laws in order to find a solution to the problem of the genesis of forms and laws of thought. Sergii Krymskyi, following the style of scientific thinking, looked for the prospects for developing this issue in various fields of knowledge.
\end{abstract}

Keywords: Sergii Krymskyi; Ukrainian philosophy; Soviet philosophy; Marxist-Leninist ideology; forms of thinking; laws of thinking; logic

Received: January 15, 2019; accepted: February 21, 2019

Future Human Image, Volume 11, 2019: 113-119.

https://doi.org/10.29202/fhi/11/13

(C) Turenko, Vitali, 2019

(C) Yarmolitska, Nataliia, 2019 


\section{Introduction}

The Ukrainian philosophical tradition has a long history and embodies various stages: from the Kievan wisdom to the post-Soviet modern philosophical thought. At present, we can observe that research on the Soviet period of the existence of philosophy in our lands is of particular importance. This is due to the lack of comprehensive and systematic studies devoted to the philosophy of Ukraine in the second half of the twentieth century, and the fact that existing scientific studios, for the most part, have the character of essayism and memoiristics. Accordingly, an important study of the Ukrainian philosophy of this period appears in the context of key figures and ideas. Applying precisely the historicalphilosophical methodology. Undoubtedly, one of the most famous thinkers of this period is Sergii Krymskyi (1930-2010).

It should be noted that there are a number of scientific studies devoted to Soviet philosophy in general and the figure and legacy of Sergii Krymskyi particularly, namely Maria Abyzova [Abyzova, 2015], Liubov Drotianko [Drotianko, 2015], Anatoliy Konverskyi, Ihor Bychko and Ivan Ogorodnyk [Konverskyi at al., 2005], Andriy Melnyk [Melnyk, 2015], Petro Yolon [Yolon, 2010]. However, most of them consider the legacy of Sergii Krymskyi at the turn of the $20^{\text {th }}-21^{\text {st }}$ centuries, while the studies of scientific works of the Soviet period of the Ukrainian philosopher is only a passing one and in fact, the topic of understanding the phenomenon of thinking is ignored.

\section{Problems of genesis forms and principles of thinking in the conception of Sergii Krymskyi}

First of all, it should be emphasizes that "The Soviet ideology expansion over Ukrainian intellectual culture caused fundamental changes in the topics and the way of providing of philosophical inquiries and research within all subfields of philosophy. The variety of topics and methods of philosophical research was reduced to Marxist-linked topics and Marxist-Leninist dialectics. Aim and scope of any philosophical research were strictly determined by a general communist party strategy of social development. Moreover, one of the fundamental intentions of the Soviet totalitarian science and philosophy was to destroy a national authenticity and cultural distinction of USSR members and its research in Humanities" [Tytarenko \& Rudenko, 2018: 109].

Despite the fact that the order of the time required scholars to study science in the light of the struggle of materialism with idealism, in which the problem of the nature of forms of thinking was fundamentally ideological, and the tasks of the contemporary science focused on intensifying the struggle against bourgeois philosophy, most scientists managed to defend their point of view (although and in somewhat veiled form). It should be noted on the existing party repressive pressure in the sphere of culture, science and art, where the original developments in the social sciences did not have importance, and philosophical scholars were subjected to ideological attacks and political accusations.

However, this could not stop scientists from the 1960 s and ' 70 s from theoretical developments in the field of logic, methodology and philosophy of science, integrating together scientists in many fields of knowledge (mathematics, cybernetics, theoretical physics, philosophical and mathematical logic, etc.). To the circle of such innovators, scientists also belonged to Sergii Krymskyi, trying to express their own thoughts, avoiding the Soviet ideological principles 
Though he was to certain limits of the studies, the scientist concentrates his quest for the problems of dialectical logic. He tries to analyze the main stages of the evolution of logical forms and principles in the process of anthropogenesis, proposes hypotheses about the dating of their appearance and the ways of forming the modern linguistic and logical structure of thought.

Sergii Krymskyi with the help the scientific search and comprehension of the actual material from various branches of knowledge (anatomy, anthropology, history of language, theoretical linguistics, psychology, etc.), concludes that if the empirical data of all sciences on the same phenomenon coincide, then they are a reliable fact, and only through analysis and comprehension of reliable facts one can make substantiated generalizations.

It is on this source bases the leading idea of Sergii Krymskyi in relation to the study of the formation of logical thinking, in this, he adheres to his own interpretation but does not deal with the retelling of comments and comments of other people's texts. This heuristic orientation led the scientist to philosophize, which was positioned as a logic, methodology, and philosophy of science, which became innovative in the Ukrainian environment.

It should be noted that while adhering to the fact that the possession of dialectic involves the ability to look at the problem from a variety of philosophical positions, Ukrainian philosopher concentrates on the study of the dialectical nature of the forms of thinking. Currently, scholar notes that

“...the forms and laws of thinking are not a direct reflection of reality (otherwise would disappear difference between the form and content of thought), but the result of historical development thinking, it's the sublimate multibillion repetition practice reflection of the objective world.

Logical forms and laws, as a consequence of the abstraction from the concreteness given in each elementary act of reflection of the objective world, are not reduced, however, to it (concrete), but represent the product of a long theoretical work of thinking, the product of the development of the practice of knowledge. In other words, the forms and laws of thinking are abstracted from reality in the historical process of the development of cognition" [Krymskyi, 1962: 14].

With the development of practice, learning every act of reflection of objective reality can turn into reality. This means that each level of abstract thinking ability, to each the period of inner experience and practice meets a certain degree of knowledge development logical forms and laws, as we know, is always logical, since it is in the direction of objective reality.

The attempt of metaphysical considering forms and laws of thinking as evidence essences found its manifestation in the philosophy of Immanuel Kant. Instead, Sergii Krymskyi draws attention to the fact that this led to the impossibility of finding the material, the experiential basis of thinking and led to a priori, that is to idealism. On the other hand, such an attempt to identify idealistically the forms and laws of thinking with objective reality (most clearly expressed in Georg Hegel) leads to the refusal to consider the process of the emergence of forms of thinking in the development of socio-historical practice. It connected with that they are regarded as the most objective things, and not as a dialectical process of reflection of the development of these things. Such an idealistic point of view leads to metaphysics. It is no coincidence - notes Sergii Krymskyi, - Hegel does not even considering upon the question of the evolution and the emergence of forms and laws of thought, but considers only the 
mutual transition of existing forms of thinking, discovered by Aristotle [Krymskyi, 1962: 1516]. In this, we see certain critical moments in Sergii Krymskyi in relation to Georg Hegel's philosophy, in particular with regard to the issue of evolution and the emergence of forms and laws of thinking.

Therefore, such Sergii Krymskyi's views are evidence suggests that Soviet scholars were not openly able to express their thoughts, and their studies had to be adapted to "ideologically correct" interpretations and to remain within the framework of the Marxist-Leninist tradition. However, despite this, they continued to work and tried to convey their thoughts to the great public.

Continuing the theme of what constitutes logical forms and what their epistemological and dialectical nature is, Sergii Krymskyi noted that forms of thinking — these are the general structures of all conceivable content, they express the logical ways of the relationship of the most common elements of each thought.

"Such general ways of the interconnections of the common elements of thinking is the concept in which the essential features of the cognitive object advocate for thinking in the structure of abstract unity; judgment in the subject-predicative structure of which reflects the subject-attributive and other relations of the objective world; logical consequences that propose a three-member structure of the mediation of the subject and the predicate by the average term in which the unity of the object and the sign is determined by the third moment of each contradiction - its basis" [Krymskyi, 1962: 16].

These general structures of thought were first expressed by Aristotle, and Georg Hegel approached the same question very closely, who expressed his own opinion on the objective analogue of logical figures. Such studies lead to Sergii Krymskyi to the conclusion that the forms of thinking, even at a relatively high level of their structural organization, act as a logical expression of objects in the "logic" of things that is, expressing the real process of historical development. This means that the practice of cognition and transformation of the world, remaining logical figures, as if they "deliver" their knowledge, translating the historical process into its logical adequacy, which inevitably leads to the unity of the historical and logical [Krymskyi, 1962: 19].

Thus, Sergii Krymskyi comes to the conclusion, that no fundamental issue of logic cannot be solved only within the logic itself. It connected with that since every part of the great and complex problem of materialistic interpretation of forms of thinking can be understood only on the basis of the unity of logic, epistemology and dialectics. Just as the forms of thinking, a certain evolution passes and logical laws. However, Sergii Krymskyi points out that a certain time of the formation of logical laws has not yet been the object of research in philosophical literature. Logical laws are not the laws of the entire material and spiritual world, says the scientist; they arise only in the process of a long abstract work of thinking. Thus, the laws of logic are given not in the directly specific meaning of thinking, which is determined by the material, external experience, but in the historical development of this content, development, which, at the same time, causes the forms of thinking [Krymskyi, 1962: 103-104].

It should be noted that this Soviet thinker acknowledged that in his research he tried to interpret the principle of unity of logic, epistemology and dialectics in terms of finding a specific mechanism through which the process of logical formation will coincide with the process of transition from the abstract category to the concrete, as well as with the process of dialectic knowledge of the truth - the basic epistemological regularity of the transition from living contemplation to the abstract of matter and from it to practice. 
Consequently, the analysis of the genesis of the forms and laws of thinking, which conducted by Ukrainian philosopher makes it clear that the unified development line from direct practical manipulation of objects that can functionally have a semantic and logical load, creates a system of so-called concrete action-oriented thinking and leads to thinking of theoretic. In this process, the main role is played by three mechanisms: the mechanism of creating the motor image of the object in the system of actions, the mechanism of reproduction of the motor image of the object from the object itself and the mechanism of formation of the constant meaning of words as a means of consolidating the individual experience by the collective experience. Soviet thinker notes that these mechanisms are used by cybernetics to model mental activity [Krymskyi, 1962: 122].

\section{Sergii Krymskyi on theoretical thinking and creative cognition as functions of the cognitive process}

For some time, the subject of research by Sergii Krymskyi was scientific thinking and a way of cognition. The scientist noted that the very way of knowing is determined by the general dialectics and in particular by formal logic systems. However, the laws of dialectics and logic do not change in the usual sense, they are only specified and enriched. It is with this particular specification that one can distinguish the features of the scientific thinking of certain historical epochs. According to Sergii Krymskyi, the concept of "style" is the concept that adequately corresponds to the historical peculiarities of the sciences of the thinking.

Therefore, describing the changes in the theoretical activities of mankind in the era of scientific and technological revolution, it is important to indicate changes in the style of scientific thinking. As you know, the concept of style in science was introduced in the $18^{\text {th }}$ century Johann Winckelmann in connection with the need for dating the monuments of material culture and archaeology. In general talking about the very concept of style, it is applied to the processes of scientific creativity, it, as well as different epochs, is associated with a certain canon and standard representations on which the world of science is built on a certain stage of its historical development. Such canon of a particular type of scientific explanation of reality. So for every epoch it is common and is manifested in the development of major research directions, causing some standard representation in all contexts metalanguage's fundamental theories of his time.

However, according to Sergii Krymskyi, one should not consider that the style of scientific thinking is limited to the type of scientific explanation, "because scientific thinking is not limited to functioning only at the level of the scientific picture of the world, it is first and foremost embodied at the level of development of specific scientific theories" [Krymskyi, 1970: 74].

However, according to Soviet thinker, one should not consider that the style of scientific thinking is limited to the type of scientific explanation, "because scientific thinking is not limited to functioning only at the level of the scientific picture of the world, it is first and foremost embodied at the level of development of specific scientific theories" [Krymskyi, 1970: 74].

It should be noted that analyzing the features of scientific thinking Sergii Krymskyi points out that they coincide with those definitions of the features of scientific thinking of the $20^{\text {th }}$ century, which in one or another set and for various reasons are given in the analysis of natural science. Of course, these features cannot completely characterize the entire style of modern 
scientific thinking, but they are its essential modules. However, Sergii Krymskyi distinguishes one of the main features of his contemporary scientific thinking, which is determined by a qualitative leap in the history of knowledge, associated with the transition from "study of substrate qualities (as the main direction analysis of object) to the method of exploring operations on objects (in the special sense of transformation), in which the substrate and properties are manifested, and the very possibility of existence and transformation of these objects" [Krymskyi, 1970: 77].

This method was first formulated in mathematics (as an idealized representation of the fact of the condition of the geometric figures by the rules of their construction), which later became necessary for science, giving rise to a new type of abstraction - the abstraction of the transporting of the object and the replacement of its invariants. Sergii Krymskyi recognizes that it is on the basis of this abstraction determined the main fragments of the physical picture of the world are determined. However, the scientist warns against the inadequate use of the very concept of "style", when the presentation, "typical of heuristic methods of operation of the one-sided abstractions of discreteness, finitude etc., intertwine with the ontological status of these categories. After all, ontologically one cannot give any advantage of finiteness to the infinite, the probability of necessity, the discreteness of continuity, etc. These categories are organically linked, as evidenced by the content of modern science..." [Krymskyi, 1970: 79].

Describing the style of scientific thinking, Sergii Krymskyi notes, that sometimes the modern scientific creativity of knowledge starts from the inside, from the theoretical thinking, while thinking about the restoration of the normal course of the cognitive process, while providing the conditions for the construction of the theory based on observation data and experimental verification its results.

According to the scientist, it is these changes in the structure of the cognitive act adequately expressed by the concept of the style of thinking in modern science, "as a concrete embodiment of the categorical net and methodological principles, which corresponds to the scientific picture of the world" [Krymskyi, 1970: 82].

However, Sergii Krymskyi emphasizes that for the style of the natural science of the nineteenth century there were characteristic hydrodynamic images, whereas for the present stage of science the image of a stochastic automaton is typical. In the very image of a stochastic automaton, these principles and canonical representations of the style of contemporary natural science are the principle of modelling, the idea of mathematical nature and the hierarchy of levels of its construction, the structural-functional approach, etc., as well as the principles of invariance, symmetry and simplicity, and the features of finitism, discreteness and stochasticity.

Ukrainian philosopher warns that it is the hypertrophy of these representations that can lead to a peculiar phantom of scientific thinking. "Such a phantom is the idea of stochasticity, as the main feature of modern scientific style" [Krymskyi, 1970: 83]. In addition, he was disturbed on the question concerning the mathematization of scientific thinking, whose nondefinition would inevitably lead to the extrapolation of this process to the infinite perspective of the development of science, while the process of mathematization has qualitative boundaries, which are closely related to the development of the canon of mathematical thinking in the sciences. 


\section{Conclusions}

Consequently, in spite of the fact that the philosophical questions for Ukrainian scholars of the Soviet period were in an ideological framework, it did not stop them from studying in those branches of philosophical knowledge that was at that time on the periphery of research. On the example of comprehension of the problem of practice in the legacy of Sergii Krymskyi, we can see that, strict regulation of scientific research in philosophy, certain qualitative changes in philosophical thought took place, which for a long time was clogged with grips of Marxist doctrine, but it failed to stop the emergence of diverse philosophical views. From the above, we can conclude that the philosophical studies of Sergii Krymskyi were authentic, but they were not independent of the direction of the Soviet regime and censorship but were directed at the unceasing knowledge and understanding of the new, which undermined the usual ideas and contradicted the established ideological norms.

\section{미] References}

Abyzova, Maria. S. Krymskyi: Philosopher of Transitional Period, Studia Istorii Filosofii, 4 (6), 2015: 107-118. https://doi.org/10.12775/szhf.2015.052/

Drotianko, Liubov. Science as a cultural phenomenon in the philosophical heritage of S. Krymskyi, Visnyk NAU. Series: Philosophy. Culturology, № 2 (22), 2015: 10-14.

Konverskyi, Anatoliy, Igor Bychko and Ivan Ogorodnik. Philosophical Thought at Kyiv University: History and Present. Kyiv, Center for Educational Literature, 2005.

Krymskyi, Sergii. Genesis of forms and laws of thinking. Kyiv, Publishing house of the Academy of Sciences of the Ukrainian SSR, 1962.

Krymskyi, Sergii. On the style of thinking in contemporary natural science, Philosophical Thought, 5, 1970: 72-83.

Melnyk, Andriy. In the newspaper the philosopher: Serhiy Krymskyi as a public intellectual, Social Communication, Volume 1, (2015): 19-27. https://doi.org/10.1515/sc-2015-0003

Tytarenko, Vadym and Sergii Rudenko. Kant's Studies in Ukrainian Philosophy of the Soviet Period, Future Human Image, 9, 2018: 107-114. https://doi.org/10.29202/fhi/9/11

Yolon, Petro. Life in philosophy and philosophy in life, Krymskyi Sergii Borisovich, Biobibliographers index, Kyiv. 2010. 